\title{
A novel inflow cannulation strategy for pediatric mechanical circulatory support in small left ventricles
}

\author{
Michael Ma, MD, ${ }^{\mathrm{a}}$ Vamsi V. Yarlagadda, MD, ${ }^{\mathrm{b}}$ David N. Rosenthal, MD, \\ Stanford, Calif \\ From the ${ }^{\mathrm{a}}$ Division of Pediatric Cardiothoracic Surgery, Department of Cardiothoracic Surgery, and ${ }^{\mathrm{b}}$ Division of \\ Pediatric Cardiology, Department of Pediatrics, Lucile Packard Children's Hospital, Stanford University, Stan- \\ ford, Calif. \\ Disclosures: D.N.R. reports grant support from Berlin Heart (Berlin, Germany) and educational conference sup- \\ port from HeartWare (Framingham, Mass). All other authors have nothing to disclose with regard to commer- \\ cial support. \\ Received for publication Jan 6, 2017; revisions received Feb 20, 2017; accepted for publication March 5, 2017 ; \\ available ahead of print April 14, 2017 \\ Address for reprints: Michael Ma, MD, Lucile Packard Children's Hospital, Stanford University, 780 Welch Rd, \\ Falk Building, CVRB, MC 5407, Palo Alto, CA 94304 (E-mail: mma@stanford.edu). \\ J Thorac Cardiovasc Surg 2017;154:e47-8 \\ $0022-5223 / \$ 36.00$ \\ Copyright (C) 2017 by The American Association for Thoracic Surgery \\ http://dx.doi.org/10.1016/j.jtcvs.2017.03.034
}

Mechanical circulatory support (MCS) in infants with isolated diastolic dysfunction remains elusive. The small, restrictive ventricle is difficult to support from standard apical or atrial inflow cannulation, secondary to dynamic flow obstruction or thrombus formation in the setting of thickened ventricular myocardium or compliant, redundant left atrial tissue. Considering such pitfalls, we attempted a novel inflow cannulation technique to provide stable mid/longterm left-sided support.

\section{CASE REPORT}

A 10-month-old 7.2-kg girl was referred after a murmur was noted on her well-child visit. Transthoracic echocardiography demonstrated critical aortic stenosis, preserved systolic function, severe hypertrophy, noncompaction, and diastolic dysfunction. Aortic valve balloon dilatation was performed without success, and the Ross-Konno operation was completed.

The patient's postoperative course was marked by a slow convalescence in the setting of long-standing diastolic dysfunction, left atrial hypertension, pulmonary vascular hyper-reactivity, and concomitant right ventricular dysfunction. Acute instability prompted institution of venoarterial extracorporeal membrane oxygenation 4 months after surgery. Continued fragility prompted transition to longerterm MCS in the form of a Berlin Heart (Berlin, Germany) EXCOR implantation as a bridge to recovery versus transplantation. In consideration of the described difficulties, a novel inflow cannulation technique was used.

Reentry sternotomy was performed. An additional inferior vena cava cannula was placed, and the venoarterial extracorporeal membrane oxygenation circuit transitioned to cardiopulmonary bypass. The heart remained warm and beating. Bicaval snares were applied, a right atriotomy was performed, and the interatrial septum was excised to enable direct anastomosis of a 10-mm ringed

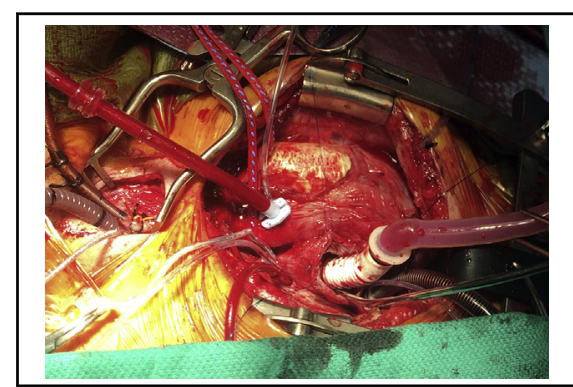

Novel inflow cannulation strategy, demonstrating conduit anastomosis to atrial septectomy.

Central Message

A novel left ventricular assist device inflow cannulation, positioned at the atrial septum, may improve our ability to support patients with severe diastolic ventricular failure.

See Editorial Commentary page e49.

polytetrafluoroethylene (Gore-Tex; WL Gore \& Associates, Flagstaff, Ariz) graft attached to a 6-mm Berlin Heart inflow cannula. The right atriotomy was then closed around this conduit (Figure 1). A 10-mm nonringed polytetrafluoroethylene (Gore-Tex) graft attached to a 6-mm Berlin Heart outflow cannula was anastomosed to the ascending aorta via a side-biting clamp. Both cannulae were tunneled through the chest wall and attached to a centrifugal pump (Sorin Revolution; Sorin, Milan, Italy) after appropriate de-airing maneuvers. Cardiopulmonary bypass was weaned

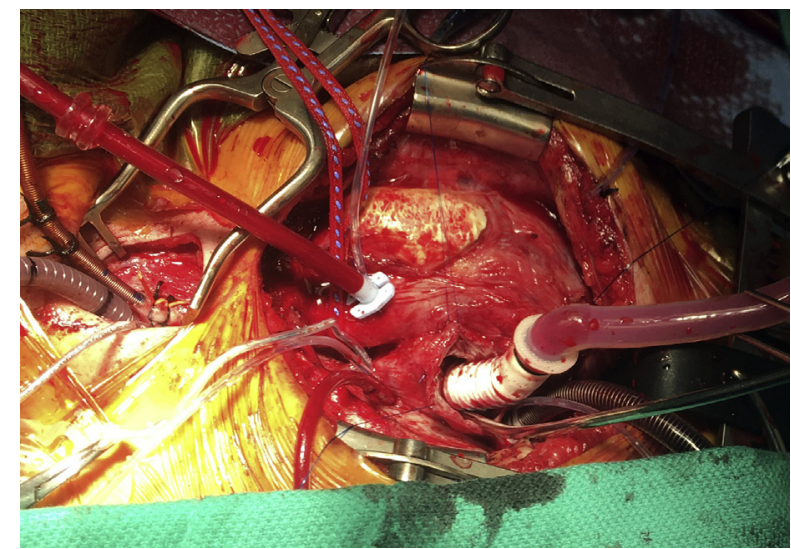

FIGURE 1. Novel inflow cannulation strategy, demonstrating conduit anastomosis to atrial septectomy. 


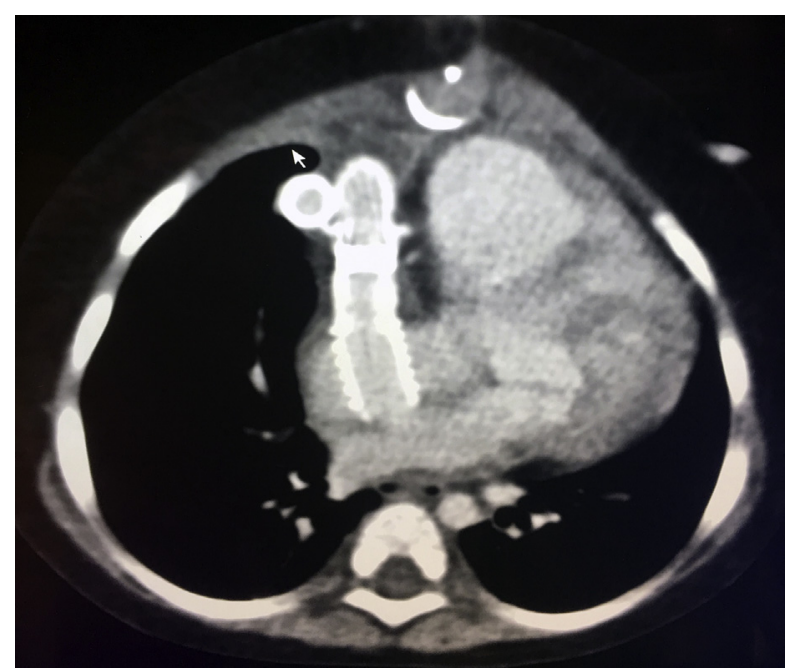

FIGURE 2. Surveillance postoperative computed tomography scan, demonstrating appropriate cannula position without obstruction or clot.

as ventricular assist was up-titrated. Left ventricular support reduced left atrial hypertension from $20 \mathrm{~mm} \mathrm{Hg}$ to 7 to $9 \mathrm{~mm} \mathrm{Hg}$. Hemostasis was ensured, and the sternum was closed.

The patient's postoperative course has been uneventful, notable only for a small brain hemorrhage with no clinical neurologic deficit. Anticoagulation was gently transitioned from heparin alone to a goal regimen of enoxaparin (targeting anti Xa 0.6-1.0), aspirin $30 \mathrm{mg} / \mathrm{kg} / \mathrm{d}$, clopidogrel $0.8 \mathrm{mg} / \mathrm{kg} / \mathrm{d}$, and dipyridamole $3.75 \mathrm{mg} / \mathrm{kg}$ every 6 hours. The centrifugal pump was transitioned to a Berlin Heart EXCOR 10-mL pump on the second postoperative day. Surveillance computed tomography scan at 1 month delineated a well-positioned inflow cannula without obstruction or thrombus (Figure 2), and catheterization at 6 weeks demonstrated excellent and continued reduction in left atrial hypertension (left atrial pressure $3 \mathrm{~mm} \mathrm{Hg}$, cardiac index $4.2 \mathrm{~L} / \mathrm{m}^{2}$, pulmonary vascular resistance index 3 Woods unit- $\mathrm{m}^{2}$ ) without inotropic support. The patient has minimal activity restrictions, is growing and developing appropriately, and remains clinically stable on the ward.

\section{DISCUSSION}

Experience with MCS in infants has relied heavily on the use of extracorporeal membrane oxygenation. With its approval for North American use in 2012, the Berlin Heart EXCOR has become a reliable option with adequate outcomes for mid/long-term support in patients with dilated cardiomyopathy. Patients with hypertrophic or restrictive cardiomyopathy and those with postcardiotomy ventricular dysfunction continue to have poor outcomes, which in part may be due to technical difficulties with maintaining reliable support in the setting of cannula dysfunction. ${ }^{1,2}$

Many studies comparing atrial and ventricular inflow corroborate poorer performance with the former, although this strategy may be attractive in patients like our own, in whom the left ventricular cavity size precludes placement of an apical cannula. Ventricular clot formation, found more commonly with an atrial inflow strategy, may be less problematic in this situation, because the left ventricular cavity size is inherently small and contractility is preserved. ${ }^{3}$

This technique also addresses concerns with collapse of redundant atrial tissue around the right upper pulmonary vein, because the inflow orifice is flush against the left atrial wall at the interatrial septum. Eghtesady and colleagues ${ }^{4}$ described a similar strategy in the reverse direction, as an outflow cannula for a main pulmonary artery to left atrial paracorporeal oxygenator shunt in the setting of significant pulmonary hypertension. Its use was devised after traditional atrial cannulation resulted in excessive clot formation. ${ }^{4}$

\section{CONCLUSIONS}

Providing robust MCS for infants with diastolic dysfunction has been met with poor outcomes, which in part may be due to a lack of reliability in the implementation of existing devices. A modified inflow cannulation strategy, taking account of anatomic variables specific to this population, may provide a more robust strategy for support. Continued investigation also may enable broader application to pediatric and adult patients with hypertrophic cardiomyopathy, who are currently difficult to treat.

\section{References}

1. Fraser CD, Jaquiss RD. The Berlin Heart EXCOR pediatric ventricular assist device: history, North American experience, and future directions. Ann N Y Acad Sci. 2013;1291:96-105.

2. Hetzer R, Kaufmann F, Delmo Walter M. Paediatric mechanical circulatory support with Berlin Heart EXCOR: development and outcome of a 23-year experience. Eur J Cardiothorac Surg. 2016;50:203-10.

3. Korakianitis T, Shi Y. Numerical comparison of hemodynamics with atrium to aorta and ventricular apex to aorta VAD support. ASAIO J. 2007;53:537-48.

4. Hoganson D, Gazit A, Boston U, Sweet S, Grady RM, Huddleston CB, Eghtesady P. Paracorporeal lung assist device as a bridge to recovery or lung transplantation in neonates and young children. J Thorac Cardiovasc Surg. 2014;147: 420-7. 